\title{
New insights in understanding dental caries and periodontal disease: the avalanche model
}

\author{
Peter Gaengler ${ }^{1}$, Ljubisa Markovic ${ }^{1}$, Dagmar Norden ${ }^{2}$, Rainer A. Jordan ${ }^{1}$ \\ ${ }^{1}$ Department of Operative and Preventive Dentistry, University of Witten/Herdecke, Witten, Germany; peter.gaengler@uni-wh.de \\ ${ }^{2}$ Ordination, Rheinstraße 1826382 Wilhelmshaven, Germany
}

Received 12 October 2009; revised 10 November 2009; 13 November 2009.

\begin{abstract}
Biology is based on evolution; therefore, eucariotes like plants, animals and human beings are living in harmony with their procariote ancestors. If this is obviously the normal way of life, then pathobiology follows the same basic principles. The highly complex harmony of the living world may be disrupted, and a punctuated disease starts which is different from the health equilibrium. To reflect this biological archetype on the main diseases in dentistry - caries and periodontitis - the avalanche model is being proposed based on scientific and clinical evidence. This way of argumentation does influence the strategic planning of preventive and curative programmes in dental research as well as in daily practise.
\end{abstract}

Keywords: Dentistry; Dental Caries; Etiology; Model; Pathology; Periodontal Disease

\section{INTRODUCTION}

The role of dental caries as a health related sociological phenomenon goes back to the 10th millenium $\mathrm{BC}$, at the end of the last ice age, when raising temperatures in the flood plains of the fertile crescent allowed the cultivation of wild corn [1]. As a consequence, the fundamental change from a nomadic hunting-gathering way of life to settled farming and agriculture in man took place [2]. The development of the grinding stone was an important milestone during the continuous process of refining food. Consequently, the highly abrasive and fibre rich food of the prehistoric population was being more and more replaced by a soft diet consisting of pastries and pasta. In the $2^{\text {nd }}$ millennium $\mathrm{BC}$, increasing incidence of dental caries - though on a low level - inspired the creation of the very first etiologic model for tooth decay in human history: the concept of the tooth worm causing caries and periodontal disease. Paleoantropologic examination of skulls showed a low prevalence of dental caries $(\mathrm{Pa}-$ ganelli C. Dental caries frequency in adult egyptian mummies. Personal communication. Valdaora, 2006) less than $10 \%$ [3] increasing up to $25 \%$ in medival times [3]. During the transatlantic slave trade and the beginning of the industrial processing of cane sugar in North America and Europe, dental caries prevalence went up to $50 \%$ reaching a frequency of almost $100 \%$ in all industrialised countries today [4]. Sociologically, the dramatic increase and spread of dental caries in human society can be seen as a consequence of civilisation and industrialisation in food production. From a functional point of view, it seems to be a consequence of the absence of masticatory abrasion and tribological attrition caused by dramatic changes in diet [5]. Thus, non-opened fissures and proximal sites show the highest rates of affection, when no longer exposed to abrasive and attritional wear. These presumptions are supported by comparative odontology. Extended occlusal wear far into the dentine core, a pulp chamber becoming smaller by forming tertiary dentine and the dentition drifting mesially by flattening the proximal contacts were shown to be a natural pattern of function in omnivorous dentitions, i.e. in dentitions of wild living boars and primates showing hardly any tooth decay [6]. The Witten Dental Caries study showed further strong correlation between tooth wear and dental caries experience in man [7]. Based on phylogenetic findings, it is supposed that a thick enamel cover and a spacious pulp lumen in omnivorous species represents an equifinality - a common characteristic in open systems converging to a dynamic equilibrium - in which the pulp is a spaceholder for replacement with tertiary dentine to compensate the decreasing thickness of enamel and dentine caused by attrition and abrasion [8].

\section{PUNCTUATED EQUILIBRIA AS A BIOLOGIC PRINCIPLE}

Clinical observations have shown that caries and periodontal diseases have a chronic-cumulative character and no continuous way of progression. They lead to the con- 


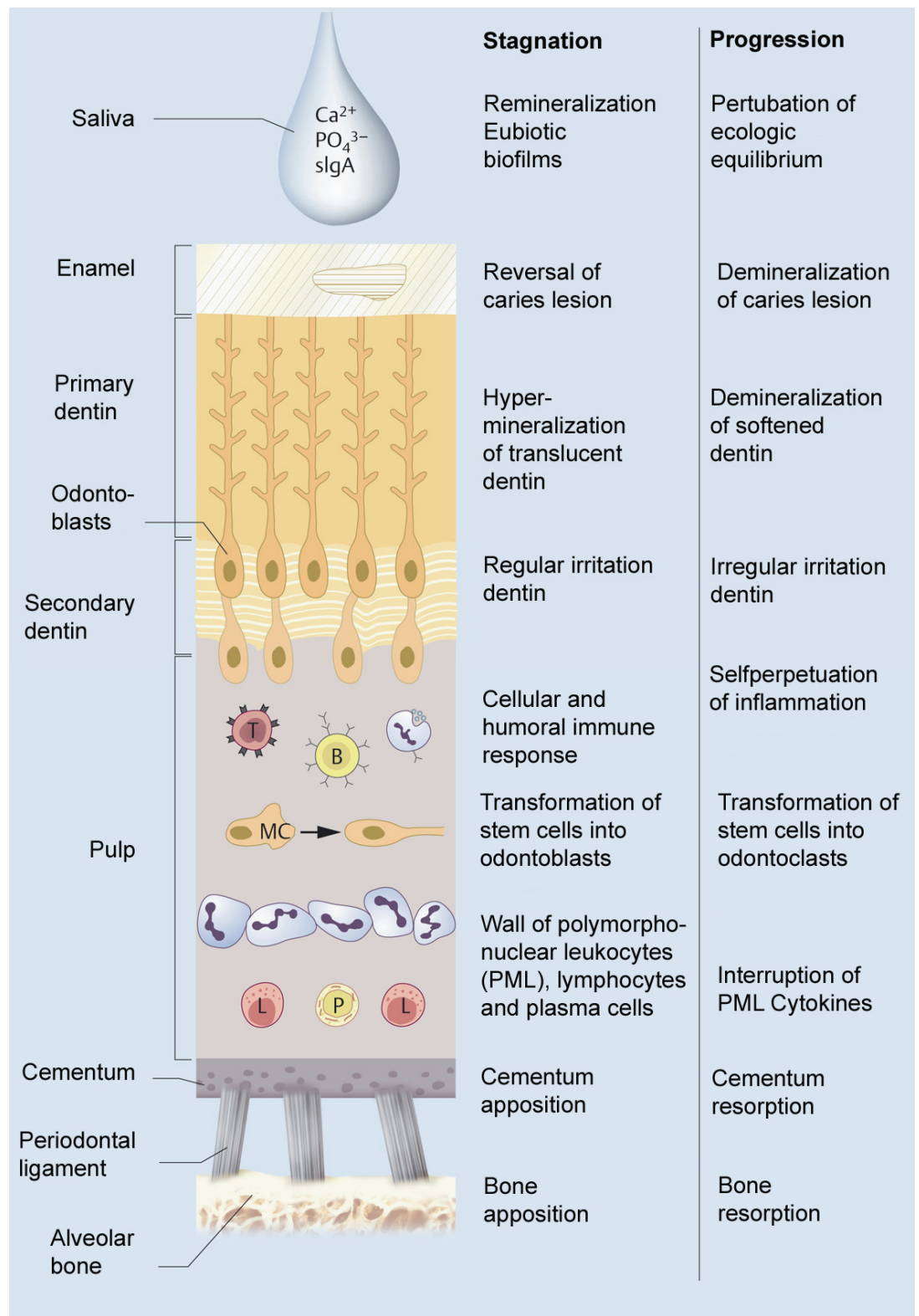

Figure 1. Biomineralisation consequences of the pathogenesis of dental caries diseases according to the concept of progression and stagnation. Comparison of factors contributing to either bursts of disease progression or to long-lasting periods of stagnation. $\mathrm{MC}=$ stem cell $; \mathrm{T}=\mathrm{T}$ lymphocyte $\mathrm{B}=\mathrm{B}$ lymphocyte; $\mathrm{P}=$ plasma cell $; \mathrm{L}=$ lymphocyte. [21]

cept of a destructive periodontal disease pathogenesis with different types of progression showing characteristic episodes of activity and inactivity [9]. Corresponding dynamics in caries progression with episodes of demineralisation and remineralisation have already been pointed out since the 1960s [10,11]. Consequently, knowledge from both cariology and periodontology was then consolidated to one robust pathogenetic Concept of Progression and Stagnation of Dental Caries and Periodontitis noticing epidemiologic, historic, immunologic, odontologic, physiologic and sociologic perceptions [12]
(Figures 1,2). The initial stages of the diseases, pre-caries as the first detectable mineral deficite and gingivitis are reversible and therefore, they are at least partly underlying a principle of progression and remission. In dental caries, the highly complex "ion whip" contributes to loss and uptake of calcium and phosphate ions in enamel and exposed dentine and cementum. This is a lifelong ongoing equilibrium, and bursts of prevailing demineralisation activity with the consequence of pre-caries and clinical caries lesions are rather occasional episodes. 


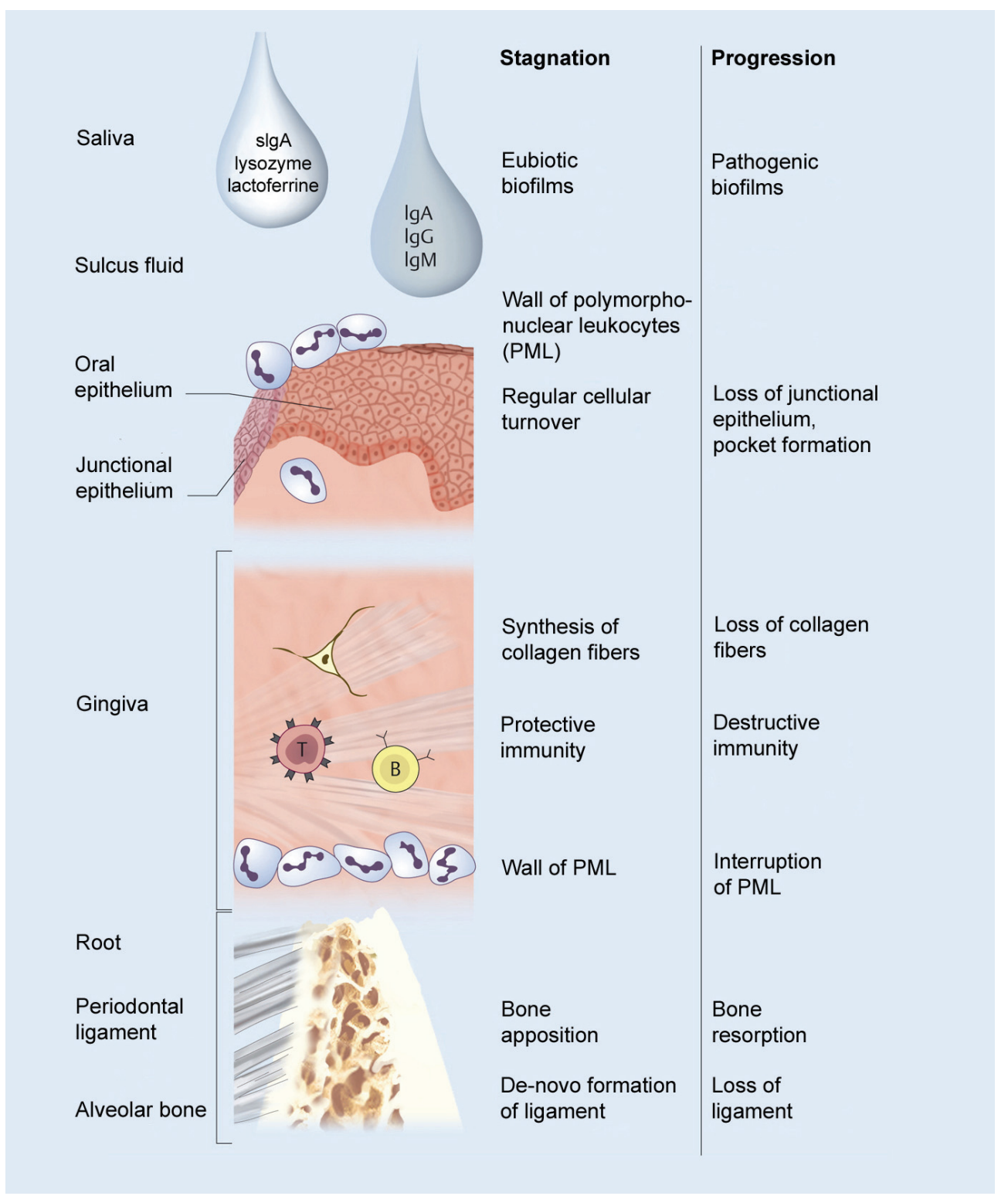

Figure 2. Biomineralisation consequences of the pathogenesis of periodontal diseases according to the concept of progression and stagnation. Comparison of factors contributing to either bursts of rapid disease progression with periodontal pocket formation or to long-lasting periods of stagnation. $\mathrm{T}=\mathrm{T}$ lymphocyte; B = B lymphocyte. [21]

In periodontal diseases, there are alternating short lasting activities of destruction (with localised immunological breakdowns) and long-lasting episodes of equilibria. From a structural biological point of view, progression means loss of connective tissue and bacterial penetration through the wall of leucocytes, stagnation means replacement of connective tissue and build-up of the wall of leucocytes.

Irregularity in biological behaviour as a principle has already been discussed in evolutionary theories in the 1970s as an alternative to phyletic gradualism of Darwin's theory of evolution, and it was later described as a general biological principle $[13,14]$. Phyletic gradualism proceeds on the assumption of long-term continuous transformation of genetic material in the majority of a population without basic episodes of stagnation. Palaeontological evidence for this stepwise transformation of slightly different forms in a common evolutionary chain could never be found. The conceptual basis for the alternative theory of punctuated equilibria is based on this assumptions: a) geographic isolation as a precondition for a genetic process of transformation and $b$ ) a homoeostatic equilibrium with rare and temporally compressed changes in the gene pool alternating with long episodes 


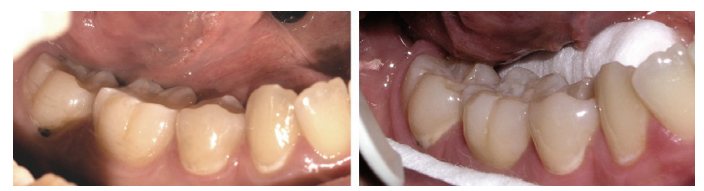

Figure 3. Initial white spot lesion (teeth 43 and 45) and brown spot lesion (tooth 47) in a young female patient, (a) start of non-invasive treatment with the daily bioavailability of fluoride by F-containing dentifrice and $\mathrm{F}$ tablets (1 mg p.d.), (b) clinical control over 5 years demonstrating reversals of the white spot lesions in canine and premolar and decreased but stable molar lesion. (courtesy of Dr. T. Lang, Witten, Germany).

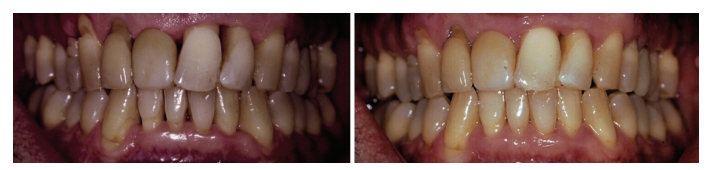

Figure 4. Periodontal condition in a young HIVseropositive patient undergoing Highly-active Antiretroviral Therapy, (a) before periodontal treatment with black triangles especially between incisors as a result of chronic marginal periodontitis triggered by necrotising ulcerative bursts, (b) 16 month after conservative treatment and a strict supportive periodontal programme with a "creeping attachment".

of stasis. The theory especially implies so-called punctuated equilibria during the early stages of speciation, while dramatic changes in the environmental conditions are taking place. If this is indeed a general biological principle, then one could try to apply this to pathobiology. Punctuationalism applied to oral medicine, then, also means, periodontal disease is a pathologic event in limited dental sites and not in the entire dentition despite the all-over presence of plaque; just like caries, that is rarely seen as a generalised event but showing age-related peaks. In palaeontology, the postulation of favourable environmental conditions for punctuations is met by geographic separation from the mother-species; in human life sciences by a locally different immunologic host reactivity [15]. The concept of pulpal reaction [16] in particular takes up the theory of biologic equilibria, as it compares pattern of pulpal reactions on dental caries progression with different functional periods of the dentition. The concept of a multifactorial disease [17] goes even one step further assuming biofilms to be a physiologic phenomenon, and demineralisations to be a simple reflection to multifactorial disturbances in a physiologic balance between the natural biofilm and all (wet) smooth surfaces. The dynamic character of dental caries and periodontal diseases has recently emphazised in the concept of cyclical progression [18]. Knowledge from microbiology confirms this view, as only $10 \%$ of all cells in human beings are mammalian; the vast amount are procaryotes, mainly bacteria. In the oral cavity, more than 20,000 genetically differentiable bacterial species were recently analyzed. They usually diversify in several clones, of which eventually one is pathogenic. As a result, many organic systems basically live in a state of symbiosis or commensalism with their microorganisms [19]. Recently, Mogens Kilian et al. suggested a scenario that commensal streptococci gradually evolved from a pathogen by genome reduction. Their study provided insight into the evolutionary history that resulted in genetically closely related streptococci with very high (S. pneumoniae) or no pathogenic potential of commensal species [20]. The comprehensive model of progression and stagnation was extended by these realisations from palaeontology and contemporary theories of evolution, from cellular biology, microbiology, and cariology to suggest the avalanche model of dental caries and periodontal diseases:

"[Punctuated equilibrium means] for the main infectious diseases in dentistry, caries and periodontitis, a promotion of the concept of progression and stagnation, when rapid punctuated bursts disrupt prolonged dormant episodes of stagnation: the macroorganism, which is otherwise living in balance with its microorganisms, reacts with an acute burst of demineralisation and/or inflammation - the episode of punctuation. This is an avalanche model, where different punctuated episodes (sun, snow, wind, hazardous snowboarder) initiate an avalanche in an otherwise highly complex system" [21].

\section{THE AVALANCHE CARIES PROGRESSION MODEL}

It would make sense to look at very few clinical examples to demonstrate the snowballing character of the avalanche caries progression model. Despite a complex variety of etiological components, the development of white spot lesions per time and per tooth mainly on smooth surfaces of dental enamel is well documented as the only evident clinical risk factor for progression or remission of subclinical pre-caries or initial caries into a surface lesion. This is also reflected in modern caries detection and assessment systems [22]. Otto Backer Dirks clearly demonstrated in a rather simple way that initial lesions may undergo remineralisation and, therefore, being arrested (10). This could be shown in longitudinal studies assessing caries over an eight year period [23]: even under highly controlled clinical conditions including oral health education and bioavailability of topical fluoride, one third of initial smooth surface caries lesions were found to turn into superficial cavities (Figure 3).

As with avalanches in winter mountains it is hard to say that a single factor of lesion progression is responsible for cavity formation, and it could easily be asked: is the shift in bacterial activity due to quorum sensing responsible, is the change in host responses due to saliva factors responsible, is temporary overload of low mo- 
lecular carbohydrates responsible, is insufficient oral hygiene responsible, or is any other factor causing progression responsible? It could also be looked at the influence of drug-induced hyposalivation as one of the main factors of root caries progression in the elderly [24]. Seemingly, it is a well-known scenario in patients attending for their routine dental check-ups to see individuals under antihypertensive and/or tranquilizing medication to develop hidden approximal or root dentine lesions within a very short time after decades of robust caries inactivity. Is the causative factor just the hyposalivation when a change in food intake and oral hygiene within the last few months is rather unlikely? Another issue is the susceptibility to secondary caries in teeth with long-term performing composite restorations with obvious marginal leakage: eighteen years old fillings were followed-up for another two years, and despite slightly increasing surface deterioration no secondary caries at the wide gaps was micromorphologically detected [25]. Plaque control at these sites was rather poor, alimentary regime stressed a slight cariogenic influence, but the avalanche did not occur.

\section{THE AVALANCHE PERIODONTAL PROGRESSION MODEL}

Per Axelsson, Birgitta Nyström and Jan Lindhe followed-up 357 subjects maintained in a preventive programme for 3, 6, 15 and finally 30 years [26]. The clinical outcome clearly demonstrated: only 21 teeth were lost due to progressive periodontitis or due to dental caries, and it was evident that the exposure of patients to a highly individualised maintenance programme in only one private dental practice provided by the same dental hygienist was mainly contributing to disease stagnation. Undeniably, the influence of various factors may have slowed down the progression of the disease, but management with a strict preventive programme retarded tooth loss dramatically, and the avalanche in most cases did not occur. On the other hand, it is also clinically and microbiologically well documented that bacterial shift due to systematic antibiotic treatment regimes may lead to outbursts of deep pocket periodontal abscesses [27]. This is obviously the result of an overgrowth of antibiotic resistant anaerobic pathogens turning a long-lasting stable periodontal disease into progressive deep pockets rapidly. Risky snowboarding with antibiotics, though, may be that fundamental change in environmental commensalism condition to initiate a punctuated equilibrium. Finally, the prevalence of oral manifestations in HIVseropositive showed necrotising ulcerative periodontitis, erythematous candidiasis and oral hairy leucoplakia to be significantly associated with the HI-viral load [28]. Again, only one factor - like the famous risky snowboarder - out of the complex host response was contrib- uting to severe disease progression and an avalanche (Figure 4).

\section{CONCLUSIONS}

Dentistry is a medical discipline. Therefore, biomedical principles in their uniqueness in the living world should be applied to dental problems and solutions. The mammalian life is mainly characterised by symbiosis and harmony of our "own" (eucaryotic) cells and of the neighborhood (procaryotic) cells, communicating to each other by signal molecules until - the avalanche goes down. This is a rare punctuated episode. And the whole dental care armamentarium should be concentrated to these episodes. Rather often we do not know what is the real cause for a given individual burst. Nevertheless, our preventive programmes and treatment strategies are powerful and effective bringing back the harmony disrupted by the avalanche.

\section{REFERENCES}

[1] Diamond, J. C. (2005) How Societies Choose to Fail or Succeed. New York: Viking.

[2] Reichholf, J.H. (2008) Warum die Menschen sesshaft wurden. Frankfurt: S. Fischer Verlag GmbH.

[3] Chazel, J.C., Tramini, P., and Pélissier, B. (2005) Observations on the severity of carious lesions throughout five periods of history. Caries Res., 39, 312.

[4] Bagramian, R.A., Garcia-Godoy, F., and Volpe, A.R. (2009) The global increase in dental caries: A pending public health crisis. Am J Dent., 22, 3-8.

[5] Arnold, W.H., Naumova, E.A., Koloda, V.V., and Gaengler, P. (2007) Tooth wear in two ancient populations of the Khazar Kaganat Region in the Ukraine. Int $\mathrm{J} \mathrm{Os-}$ teoarchaeol., in press, 7, 52-62.

[6] Gängler, P. (1986) Klinische und experimentelle Aspekte der vergleichenden Odontologie und Periodontologie. Nova Acta Leopoldina N. F., 58, 525-537.

[7] Ugur, Z.A., Gängler, P., and Karababa, A.O. (2001) Zusammenhang zwischen Kariesprävalenz und Attrition sowie Abrasion bei einer türkischen Population in Witten. Dtsch Zahnärztl Z., 56, 172-176.

[8] Gängler, P., Hoyer, I., Kosa, W., Metzler, E., and Schuder, S. (1988) Degeneration und Regeneration des Endodonts und Periodonts als Kopie phylogenetischer Zahnentwicklungsmuster. Zahn Mund Kieferheilkd Zentralbl, 76, 4-13.

[9] Socransky, S., Haffajee, A., Goodson, J., and Lindhe, J. (1984) New concepts of destructive periodontal diseases. J Clin Periodontol.,11, 21-32.

[10] Backer, D. O. (1966) Posteruptive changes in dental enamel. J Dent Res., 45, 503-511.

[11] Koulourides, T., Cueto, H., andPigman, W. (1961) Rehardering of softened enamel surface of human teeth by solutions of calcium phosphates. Nature, 189, 26-227.

[12] Gängler, P. (1985) Die Pathogenese der Zahnkaries und Parodontalerkrankungen - das Konzept von Progression 
und Stagnation. Zahn Mund Kieferheilkd Zentralbl., 73, 77-483.

[13] Eldredge, N. and Gould, S.J. (1972) Punctuated equilibria: An alternative to phyletic gradualism. In: Schopf TJ, editor. Models in Paleobiology. San Francisco: Freeman, Cooper \& Company.

[14] Gould, S.J., Eldredge, N. (1993) Punctuated equilibrium comes of age. Nature, 366, 223-227.

[15] Metschnikoff II. (1884) Eine neue Entzündungstheorie. Allg Wiener Med Ztg, 29, 307-332.

[16] Larmas, M. (2003) Dental caries seen from the pulpal side: A non-traditional approach. $J$ Dent Res, 82, 253-256

[17] Fejerskov, O. (1997) Concepts of dental caries and their consequences for understanding the disease. Community Dent Oral Epidemiol, 25, 5-12.

[18] Gilthorpe, M.S., Zamzuri, A.T., Griffiths, G.S., Maddick, I.H., Eaton, K.A., and Johnson, N.W. (2003) Unification of the "burst" and "linear" theories of periodontal disease progression: A multilevel manifestation of the same phenomen. J Dent Res, 82, 200-205.

[19] Kilian, M. (2005) Facing facts - Making sense of oral infections. Oral Biosciences and Medicine, 2, 163-165.

[20] Kilian, M., Poulsen, K., Blomqvist, T., Havarstein, L.S., Bek-Thomsen, M., Tettelin, H., et al. (2008) Evolution of streptococcus pneumoniae and its close commensal relatives. PLoS ONE, 3, e2683.

[21] Gängler, P., Hoffmann, T., Willershausen, B., Schwenzer, N., and Ehrenfeld, M. (2005) Konservierende Zahnheilkunde und Parodontologie. Stuttgart: Thieme.

[22] Ismail, A.I., Sohn, W., Tellez, M., Amaya, A., Sen, A.,
Hasson, H., et al. (2007) The International Caries Detection and Assessment System (ICDAS): An integrated system for measuring dental caries. Community Dent Oral Epidemiol, 35, 170-178.

[23] Gaengler, P., Montag, R., and Hoyer, I. (1992) Assessment of caries progression by combined index system. $J$ Dent Res, 72, 749.

[24] Bardow, A., Nyvad, B., and Nauntofte, B. (2001) Relationships between medication intake, complaints o dry mouth, salivary low rate and composition, and the rate of tooth demineralization in situ. Arch Oral Biol, 46, 413-423.

[25] Rezwani-Kaminski, T., Kamann, W., and Gaengler, P. (2002) Secondary caries susceptibility of teeth with long-term performing composite restorations. J Oral Rehabil, 29, 1131-1138.

[26] Axelsson, P., Nyström, B., and Lindhe, J. (2004) The long-term effect of a plaque control program on tooth mortality, caries and periodontal disease in adults. Results after 30 years of maintenance. J Clin Periodontol, 31, 749-757.

[27] Rodrigues, R.M., Gonçalves, C., Souto, R., Feres-Filho, E.J., Uzeda, M., and Colombo, A.P. (2004) Antibiotic resistance profile of the subgingival microbiota following systemic or local tetracycline therapy. J Clin Periodontol, 31, 420-427.

[28] Jordan, R.A., Raetzke, P., and Gängler, P. (2007) Prevalence of oral manifestations in HIV-seropositive patients undergoing highly-active antiretroviral therapy. Dtsch Zahnärztl Z, 62, 376-385. 